\title{
CÁLCULO DA ENTALPIA, ENTROPIA E VOLUME MOLAR DE VAPORIZAÇÃO UTILIZANDO REDES NEURAIS ARTIFICIAIS
}

\author{
I.N.S. DA CRUZ, H.S.DA CRUZe T.D.MARTINS
}

Universidade Federal de São Paulo, Departamento de Ciências Exatas e da Terra

E-mail para contato: isanicacio@gmail.com; tdmartins@unifesp.br

\begin{abstract}
RESUMO - Para o cálculo de propriedades termodinâmicas as equações de estado são necessárias. Porém, para a sua aplicação, a determinação de parâmetros em relação a cada substância em questão se faz necessária. Ainda, em muitos casos, tais equações apresentam limitações e/ou alguns erros. Visando a otimização dessas situações, desenvolveu-se uma rede neural artificial para o cálculo da entalpia, entropia e volume molar de vaporização. Para esse trabalho, estudou-se o comportamento de 62 substâncias divididas entre os grupos orgânicos: hidrocarbonetos alifáticos, hidrocarbonetos aromáticos, álcoois, éteres, ésteres, aldeídos, cetonas e ácidos carboxílicos. As variáveis de entrada das redes testadas foram: o índice de conectividade mássica, temperatura e pressão críticas e fator acêntrico de cada substância. Além da temperatura de saturação. A estrutura de rede que apresentou melhores resultados possui 3 camadas (5-40-3). Os erros encontrados para a entalpia foram de $31,62 \%$, para a entropia de $35,58 \%$ e para o volume molar $99,92 \%$. Este trabalho mostrou que as redes neurais artificiais possuem grande capacidade de diferenciação das substâncias e que com alguns aprimoramentos, elas podem ser utilizadas para fins práticos.
\end{abstract}

\section{INTRODUÇÃO}

As propriedades de vaporização são definidas como a diferença entre o valor medido no estado de vapor saturado e aquele no estado de líquido saturado. Tais propriedades são particularmente importantes, pois essas informações são utilizadas posteriormente na modelagem e dimensionamento dos equipamentos envolvidos.

Para seu cálculo, é imprescindível o conhecimento das propriedades de líquido e vapor saturado para as substâncias em questão. No entanto, a obtenção experimental dessas propriedades nem sempre é fácil. Por outro lado, elas podem ser calculadas por meio de equações de estado, ou de relações indiretas, as quais nem sempre são precisas. Além disso, outra desvantagem dos métodos convencionais é o fato de que o equacionamento, e a determinação dos parâmetros, precisam ser feitos para cada substância em separado.

Por esse motivo, métodos alternativos, que levam em consideração as características das substâncias para seu cálculo podem ser viáveis. Dentre eles, estão disponíveis as Redes Neurais Artificiais (RNAs), que foram concebidas de modo a imitar o cérebro humano. Elas são formadas por um conjunto de neurônios artificiais, dispostos em camadas e possuem uma capacidade notória para aprender com exemplos. 
De acordo com Silva, Spatti e Flauzino (2010), neurônios artificiais utilizados nas RNAs são não-lineares, fornecem saídas tipicamente contínuas, e realizam funções simples, como coletar os sinais existentes em suas entradas, agregá-los de acordo com sua função operacional e produzir uma resposta, levando em consideração sua função de ativação inerente. A Figura 1 ilustra o funcionamento de um neurônio artificial.

Figura 1 - Esquema de um Neurônio Artificial. Fonte: Klassen, (2008)

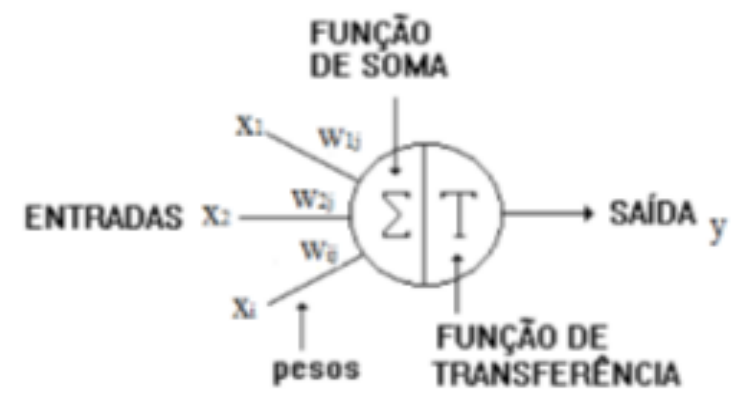

Uma das correlações existentes entre um neurônio biológico e artificial, são as ponderações exercidas pelas junções sinápticas que são representadas pelo conjunto de pesos sinápticos $\left(\mathrm{w}_{1}, \mathrm{w}_{2}, \ldots, \mathrm{w}_{\mathrm{n}}\right)$ no neurônio artificial, conforme mostra a Figura 1. As entradas $\left(\mathrm{x}_{\mathrm{i}}\right)$ do neurônio são executadas por meio das multiplicações pelos respectivos pesos sinápticos $\left(\mathrm{w}_{\mathrm{i}}\right)$. Portanto, pode-se dizer que a saída do corpo celular artificial $(\mathrm{y})$ seria a soma ponderada das entradas.

Dentro desse contexto, o principal objetivo deste trabalho é obter uma única RNA para calcular os valores da entalpia, entropia e do volume molar de vaporização de diversas substâncias, utilizando um único conjunto de parâmetros.

\section{MATERIAIS E MÉTODOS}

\subsection{Coleta de Dados}

Escolheram-se 62 substâncias de classes orgânicas diferentes, entre elas: hidrocarbonetos alifáticos, hidrocarbonetos aromáticos, álcoois, éteres, ésteres, aldeídos, cetonas, ácidos carboxílicos, além de algumas substâncias inorgânicas simples. As variáveis de entrada da rede foram o índice de conectividade mássica de cada substância, temperatura e pressão críticas, fator acêntrico, além da temperatura do estado de saturação em questão.

O índice de conectividade mássica é uma propriedade molecular que varia com a massa de cada grupo atômico e conforme estes grupos estão conectados. Esse índice é calculado pela equação (1), onde $m_{\mathrm{i}}$ e $m_{\mathrm{j}}$ são as massas dos grupos atômicos que estão conectados diretamente (Valderrama e Rojas, 2010).

$$
\lambda=\sum\left(\frac{1}{\sqrt{m_{i} m_{j}}}\right)_{i j}
$$


O índice de conectividade mássica fornece uma caracterização que leva em consideração a massa e a disposição dos grupos atômicos e pode ser avaliado como uma alternativa aos métodos de contribuição de grupos utilizados no UNIFAC.

Os dados de saída foram: entalpia, entropia e volume molar de vaporização. Seus respectivos valores foram obtidos por meio do site do National Institute of Standards and Technology (NIST,2016).

\subsection{Treinamento}

Utilizou-se o método Resilient BackPropagation como método de otimização, e a função tangente hiperbólica como função de ativação dos neurônios em todas as camadas. Foram testadas diferentes estruturas de RNAs, onde as camadas intermediárias variavam entre 1 e 2 e o número de neurônios em cada uma dessas camadas, entre 5 e 85.

A função objetivo minimizada pelo método foi o MSE (Erro Quadrático Médio), dado pela equação:

$F_{a b j}=\sum_{i=1}^{m} \frac{\left(y-y^{\prime}\right)^{2}}{m}$

em que: y é o valor estimado pela rede, y’é o valor real fornecido à rede e $\mathrm{m}$ é o número de dados experimentais fornecidos a rede. De todos os dados experimentais coletados (que totalizaram 15000), $60 \%$ foram utilizados para o treinamento, $15 \%$ para a validação e $15 \%$ para os testes. A divisão dos pontos foi aleatória e o treinamento das RNAs foi realizada utilizando-se do toolbox de RNAs do software MatLab®.

\section{RESULTADOS E DISCUSSÃO}

Após a etapa de treinamento, os resultados foram coletados e analisados. Alguns critérios foram usados para escolha da melhor estrutura de RNA, sendo eles o MSE e o $\mathrm{r}^{2}$ para as etapas de treinamento, e validação durante a etapa de treinamento.

Segundo Nowruzi e Ghassemi (2016), estruturas que apresentam baixos valores de MSE e um $\mathrm{r}^{2}$ mais próximo de 1 são indicativos para a escolha da melhor estrutura de uma RNA. A estrutura que melhor satisfez esses requisitos possui a seguinte configuração: 5-40-3 e foi escolhida por apresentar erros médios mais satisfatórios variando de $31 \%$ a $99 \%$ (vide Tabela 2). Outras estruturas também foram analisadas, tais como as apresentadas na Tabela 1.

Analisando-se a Tabela 1, é possível observar que outras estruturas apresentaram melhores $\mathrm{r}^{2}$ de treinamento e validação (em destaque). Entre todas essas estruturas, a que apresentou o maior valor no treinamento foi a estrutura 5-25-85-3. Um dos motivos que esta rede não foi escolhida deve-se ao fato de que os erros médios para essa RNA foram excessivamente altos: em relação à entalpia observou-se um erro médio de $84,55 \%$, para a entropia de $65,51 \%$, e para o volume $11092475,57 \%$.

Além da estrutura que apresentou o melhor treinamento, analisou-se também aquela que possui melhor $r^{2}$ para validação. Essa RNA possui 3 camadas intermédias, que chegou a 85 neurônios em uma delas. Essa estrutura, 5-75-80-85-3, apresentou erros pouco satisfatórios, foram estes: $94,82 \%$ para a entalpia, $101,06 \%$ para a entropia e $5989353,31 \%$ para o volume molar. 
Tabela 1 - Resultados obtidos pelas RNAs treinadas.

\begin{tabular}{ccc}
\hline Estrutura & $\mathrm{R}^{2}$ Treinamento & $\mathrm{R}^{2}$ Validação \\
\hline $\mathbf{5 - 4 0 - 3}$ & $\mathbf{0 , 9 9 1 8}$ & $\mathbf{0 , 9 9 6 8}$ \\
$5-45-3$ & 0,9819 & 0,9980 \\
$5-50-3$ & 0,9812 & 0,9959 \\
$5-5-3$ & 0,9834 & 0,9971 \\
$5-5-25-3$ & 0,9894 & 0,9973 \\
$5-5-15-3$ & 0,9736 & 0,9987 \\
$5-5-85-3$ & 0,9848 & 0,9994 \\
$5-50-85-3$ & 0,9911 & 0,9975 \\
$5-40-85-3$ & 0,9847 & 0,9998 \\
$5-45-85-3$ & 0,9899 & 0,9910 \\
$5-65-85-3$ & 0,9953 & 0,9957 \\
$5-80-85-3$ & 0,9564 & 0,9979 \\
$5-85-85-3$ & 0,9857 & 0,9920 \\
$5-80-95-3$ & 0,9913 & 0,9999 \\
$5-60-65-3$ & 0,9802 & 0,9993 \\
$5-10-10-3$ & 0,9929 & 0,9992 \\
$5-20-10-3$ & 0,9943 & 0,9996 \\
$5-30-10-3$ & 0,9807 & 0,9876 \\
$5-40-10-3$ & 0,9907 & 0,9959 \\
$5-15-10-3$ & 0,9803 & 0,9958 \\
$5-25-10-3$ & 0,9911 & 0,9959 \\
$5-35-10-3$ & 0,9966 & 0,9901 \\
$\mathbf{5 - 2 5 - 8 5 - 3}$ & $\mathbf{0 , 9 9 9 8}$ & $\mathbf{0 , 9 9 3 9}$ \\
$5-45-10-3$ & 0,9913 & 0,9987 \\
$\mathbf{5 - 7 5 - 8 0 - 8 5 - 3}$ & $\mathbf{0 , 9 8 7 5}$ & $\mathbf{0 , 9 9 9 9}$ \\
\hline
\end{tabular}

Portanto, apesar da rede escolhida (5-40-3), não apresentar os melhores $r^{2}$ das redes no geral, pode-se afirmar que os índices para essa RNA estão bem próximos do ideal e os erros foram inferiores aos calculados para as outras estruturas, como pode ser observado na Tabela 2 .

Tabela2 - Erro Quadrático Médio para o Treinamento da Rede 5-40-3 (\%)

$\begin{array}{cc}\text { Entropia de vaporização } & 35,58 \\ \text { Entalpia de vaporização } & 31,62 \\ \text { volume molar de vaporização } & 99,92\end{array}$

Além dos erros médios, é preciso verificar a capacidade de diferenciação das 62 substâncias pela RNA. A Figura 2 apresenta os valores da entalpia de vaporização, calculados pela RNA 5-40-3. Pode-se notar que tal rede possui grande poder de diferenciação das substâncias, já que cada conjunto de pontos na vertical corresponde à uma substância diferente. Isso confirma o fato de que o conjunto de parâmetros: índice de conectividade mássica, fator acêntrico, e temperatura e pressão criticas são suficientes para descrever e diferenciar cada substância no modelo obtido. 
Figura 2 - Entalpia de vaporização calculada pela RNA 5-40-3

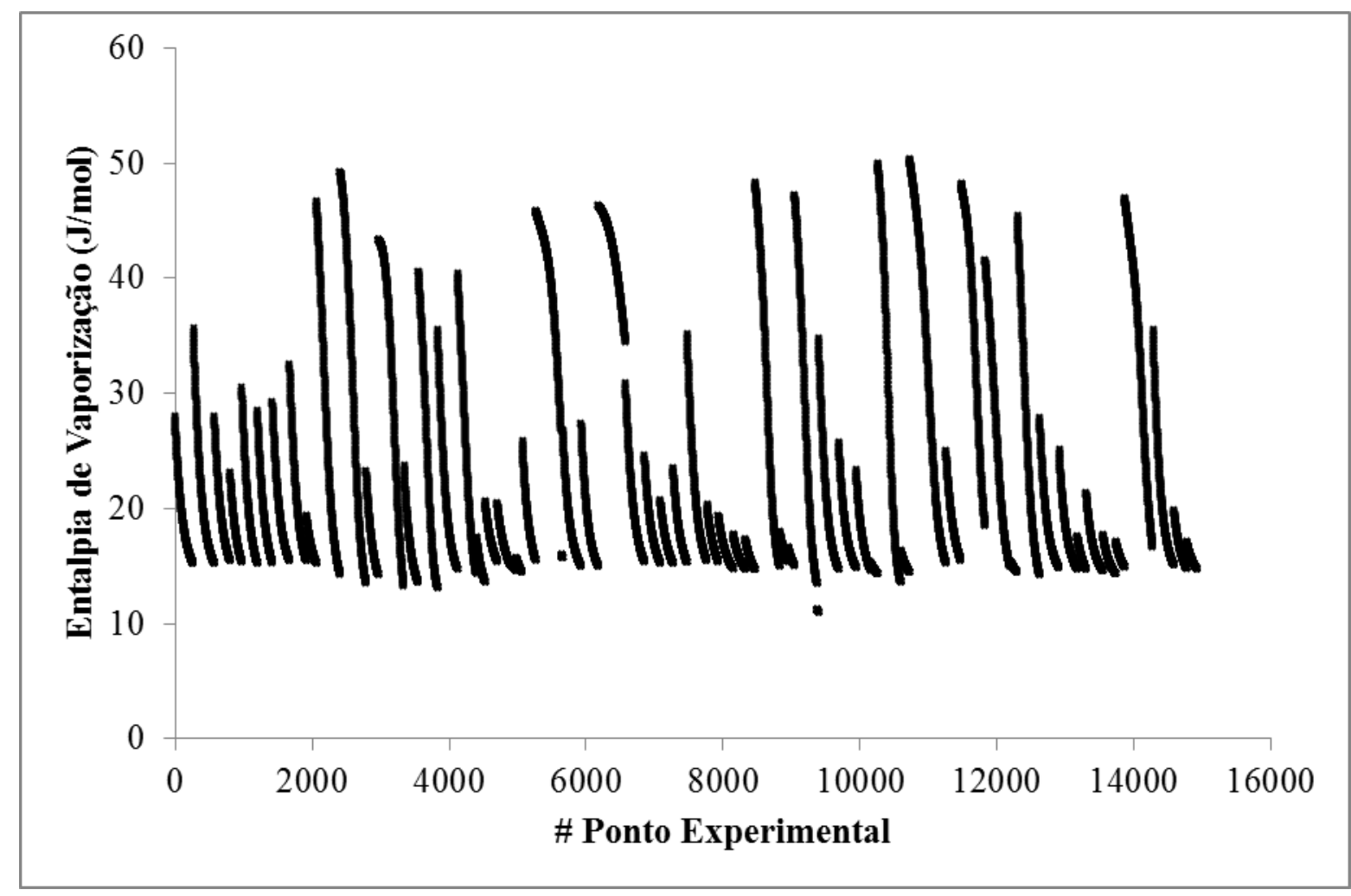

Apesar de promissor, a aplicação das RNAs ainda precisa ser estudada de forma mais aprofundada. Um método para a otimização dos erros encontrados, seria o reajuste dos pesos das camadas intermediárias. Segundo Rezende (2003), como não existe valores de saída desejados para as camadas intermediárias da rede, somente para as saídas, o ajuste dos pesos das camadas intermediárias é feito através da propagação para trás do erro da camada de saída, o que caracteriza o treinamento com backpropagation.

Além do reajuste dos pesos, outro método de aprimoração, no caso volume, seria a mudança das unidades de medida dessa propriedade. Neste trabalho, considerou-se o volume molar de vaporização em mol/L. Isso conferia valores de saída muito baixos, na ordem de $10^{-6}$. Dependendo da precisão do computador, esses valores podem resultar em um problema numérico. Portanto, quando se alterar a unidade dessa propriedade, existe a chance do valor numérico se adequar em uma faixa de valores em que os erros numéricos sejam menores.

Uma terceira opção seria alterar as variáveis de saída da RNA. Visto que a predição do volume molar não foi satisfatória, uma alternativa seria usar a RNA para calcular a pressão de saturação, energia interna e a entropia de vaporização. Assim, uma vez que se conhece também a temperatura do sistema, o volume molar poderia ser facilmente calculado utilizando-se a relação fundamental da termodinâmica:

$$
\Delta U_{v a p}=T \Delta S_{v a p}-P^{s a t} \Delta V_{v a p}
$$

em que $\Delta \mathrm{U}, \Delta \mathrm{S}$ e $\Delta \mathrm{V}$ são as variações de energia interna, entropia e volume, $\mathrm{T}$ é temperatura, 
$\mathrm{P}^{\text {sat }}$ é a pressão de saturação, e o subscrito vap significa vaporização. Além disso, a partir dessas propriedades e da Equação 4, pode-se utilizar as outras relações da termodinâmica para se calcular qualquer propriedade de interesse.

\section{CONCLUSÃO}

O principal objetivo deste trabalho foi obter uma única RNA para se calcular a entalpia, entropia e volume molar de vaporização de diversas substâncias, tendo como variáveis de entrada, características físico-químicas e a temperatura de saturação do sistema. Os resultados evidenciaram a eficiência de se calcular tais parâmetros termodinâmicos, mas por apresentarem erros médios superiores a $10 \%$, é necessário que se faça um estudo mais aprofundado. Apesar disso, as RNAs treinadas neste trabalho, possuem o poder de diferenciar substâncias a partir de um conjunto de variáveis de entrada adequado - o que confirma que tal método pode ser uma ferramenta poderosa para o cálculo de propriedades de vaporização.

\section{REFERÊNCIAS}

BRAGA, A. P.; CARVALHO, A.; LUDERMIR, T. B. Redes Neurais Artificiais: Teoria e Aplicações.p.05-55, 2000

KLASSEN, T. Uso de redes neurais artificiais para a modelagem da temperatura e da retenção de água no processo de resfriamento de carcaças de frangos por imersão. Mestrado. Universidade do Oeste do Paraná-Unioeste. Toledo, 2008.

NIST, 2016. Disponível em http://webbook.nist.gov/chemistry/fluid/ Acessado 18 de novembro de 2015.

REZENDE, S.O; Sistemas Inteligentes: Fundamentos e Aplicações. São Paulo: Editora ArtLiber., p. 160-180, 2005.

SILVA, I.N; SPATTI, D.H; FLAUZINO, R.A.; Redes Neurais Artificiais para Engenharia e Ciências Aplicadas., p. 33-42, 2010.

VALDERRAMA J. O.; ROJAS R. E., Mass connectivity index, a nex molecular parameter for the estimation of ionic liquid properties. Fluid Phase Equilib. p107-112, 2010

NOWRUZI, H.; GHASSEMI, H. Using artificial neural network to predict velocity of sound in liquid water as a function of ambient temperature, electrical and magnetic fields. Journal of Ocean Engineering and Science, v. 1, n. 3, p. 203-220, 2016. 